\title{
Reflexividades dos Aprendentes da Docência no uso de Tecnologias na Educação Básica: o que revelam os portfólios de aprendizagem
}

Késsia Mileny de Paulo Moura*

Resumo

Diante das mudanças paradigmáticas provocadas pelo advento das tecnologias na contemporaneidade, a utilização desses recursos como ferramentas pedagógicas no âmbito escolar tornou-se imperativo, no sentido de potencializar as aprendizagens dos alunos. Nesse limiar, a formação de professores não pode estar alheia a essa necessidade e deve proporcionar outras experiências que favoreçam reflexividades aos aprendentes da docência quanto aos usos das tecnologias, de forma que as práticas docentes sejam fomentadas e reverberem mudanças nas escolas de educação básica. Dito isto, este trabalho teve como objetivo captar os usos e significados das tecnologias para estudantes de Pedagogia, a partir de uma atividade prática, desenvolvida em escolas da rede de educação básica do Município de ImperatrizMaranhão, sugerida no âmbito da disciplina Informática Aplicada à Educação, do Curso de Pedagogia da UFMA. Utilizamos como instrumento de captação dos dados os portfólios de aprendizagem dos alunos, construídos ao longo da disciplina. Como conclusões mais significativas, a partir das reflexividades que a experiência lhes proporcionou, destacamos que os alunos compreenderam a emergência das tecnologias na escola, utilizaram-nas como recurso que dinamizou as atividades desenvolvidas nas aulas e puderam, em certa medida, superar a dimensão puramente técnica de uso dos aparatos tecnológicos nos processos que experenciaram. Ainda, a construção desses portfólios como instrumento de aprendizagem conduziu os aprendentes da docência a reflexões sobre as práticas e construção de saberes singulares, que podem formatar um movimento de identidade profissional.

Palavras-chave: tecnologias e educação, aprendentes da docência, portfólios de aprendizagem.

Reflections of Learning Teachers in the use of Technologies in Basic Education: what the learning portfolios reveal

\section{Abstract}

Faced with the paradigmatic changes brought about by the advent of contemporary technologies, the use of resources as pedagogical tools in the school environment has become imperative in the sense of enhancing students' learning. At this threshold, teacher training can not be unrelated to this need and should provide other experiences that favor teachers' reflections on the uses of technologies, so that teaching practices are fostered and reverberate changes in primary schools. That said, this text aims to capture the uses and meanings of the technologies of students of pedagogy, based on a practical activity developed in schools of the basic network of the Municipality of Imperatriz-Maranhão, suggested in the scope of Applied Informatics to Education Course of Pedagogy of UFMA. We used the learning portfolios of the students built throughout the course as a data capture instrument. As more significant conclusions, based on the reflections that the experience provided, we emphasize that the students understood the emergence of the technologies in the school, used them as a resource that stimulated the activities developed in the classes and could to a certain extent overcome the purely technical dimension of use of technological devices in the processes they have experienced. Moreover, the construction of these portfolios as a learning tool has led the teaching learner to reflect on the practices and construction of singular knowledge, which can shape a movement of professional identity.

Keywords: technologies and education, teaching staff, learning portfolios.

\footnotetext{
* Professora Adjunta da Universidade Federal do Maranhão-UFMA. Doutoranda no Programa de PósGraduação em Informática na Educação da Universidade Federal do Rio grande do Sul - PGIE/UFRGS. Email: kessiamileny@yahoo.com.br.
} 


\section{Introdução}

Os avanços tecnológicos trouxeram grandes alterações ao nosso cotidiano, invadiram espaços centrais de nossa atuação diária e tornaram-se imprescindíveis em muitos aspectos. Assim, um novo parâmetro foi desenhado a partir das tecnologias digitais de informação e comunicação, que suscitou e suscita outras maneiras dos sujeitos conhecerem e atuarem no mundo, em tempos e espaços diferentes. É o que nos diz Postman (1994, p. 29), quando destaca que "essas novas tecnologias alteram a estrutura de nossos interesses: as coisas sobre as quais pensamos. Alteram o caráter de nossos símbolos: as coisas com que pensamos. E alteram a natureza da comunidade: a arena na qual os pensamentos se desenvolvem".

No contexto educativo, a utilização das tecnologias de informação e comunicação (TIC) torna-se um desafio, tendo em vista não se tratar de uma simples substituição do quadro e do livro didático, pelo computador. A emergência de sua utilização na escola e na universidade deve-se ao fato de já fazerem parte do cotidiano de professores e alunos, e já terem provocado mudanças nas formas de conceber o processo de aprendizagem, como tal, as instituições educativas precisam incorporá-las ao seu fazer educativo.

Nesse viés, a formação do professor ganha complexidade e carrega inúmeras possibilidades político-pedagógicas em sua formulação, que devem ser direcionadas para um modelo que melhor configure e dê conta, do papel que o docente deve desempenhar nesse paradigma tecnológico, buscando sempre desenvolver sua atividade docente de forma contextualizada, para que melhor atenda as necessidades resultantes da dinâmica social e garanta o cumprimento de objetivos educacionais (PORTO, 2006), (SILVA, 2011).

Os processos formativos propostos não podem estar alheios aos avanços tecnológicos e as necessidades educativas que os sujeitos estão revelando. A preocupação com o uso adequado das tecnologias digitais ganha força. Contudo, para que estas apresentem alterações positivas no processo educativo, é necessário buscar compreender suas potencialidades e inseri-las efetivamente nas atividades docentes, o que requer um processo de apropriação docente nessa questão (BUZATO, 2009).

É preciso desenvolver estratégias de ensino que favoreçam o desenvolvimento de competências e o conhecimento digital do professor, mas que isso seja promovido no contexto formativo-laboral do docente, reconhecendo e valorizando o desenvolvimento 
de práticas com as TIC, nos quais teremos, inclusive, maior probabilidade de que as problematizações e os saberes de natureza pedagógica sejam assegurados.

Os cursos devem problematizar o uso das tecnologias e sistematizarem outras práticas que materializem a incorporação das tecnologias de forma significativa, preceito inclusive já estabelecido nos documentos oficiais que normatizam a educação brasileira, a exemplo da Resolução $n^{\circ} 2$ de 2015, que define as diretrizes e fixam os objetivos e as finalidades da formação de professores, ao destacar que os cursos de formação devem conduzir o egresso "ao uso competente das Tecnologias da Informação e Comunicação (TIC) para o aprimoramento da prática pedagógica e a ampliação da formação cultural dos (das) professores(as) e estudantes" (BRASIL, 2015, p. 6).

Dito isto, traçamos como objetivo captar, através dos portfólios de aprendizagem, os usos e significados das tecnologias para estudantes de Pedagogia, a partir de uma atividade prática desenvolvida em escolas da rede de educação básica do Município de Imperatriz-Maranhão, sugerida no âmbito da disciplina Informática Aplicada a Educação, do Curso de Pedagogia da UFMA.

\section{Os portfólios de aprendizagem}

Os registros dos portfólios apresentam os momentos marcantes do que foi experienciado, revelando quais foram e como cada acontecimento teve impacto, bem como os conhecimentos mobilizados para ação do sujeito que narra o processo formativo. Nesse sentido, a narrativa é (auto)formativa, ao deslocar a atenção para o sujeito e seus processos constituintes.

O potencial dos portfólios no contexto formativo também é registrado na possível “organização do portfólio em torno da arquitetura processual do construto da aprendizagem autorregulada e o fato de as narrativas dos aprendizes de professor poderem ser estruturadas, também, segundo as fases da autorregulação" (FRISON, VEIGA SIMÃO, 2011, p. 200).

Em consonância com essa natureza (auto)formativa das narrativas, Josso (2010, p. 71), afirma que "formamo-nos quando integramos na nossa consciência, e nas nossas atividades, aprendizagens, descobertas e significados efetuados de maneira fortuita ou organizada, em qualquer espaço social, na intimidade com nós próprios ou com a 
natureza", o que nos aproxima da compreensão da profissão como constituição do aprender a ser em processo, na ocasião em que o narrador organiza, controla e mobiliza estratégias autorregulatórias, que estimulam sua reflexibilidade e, por conseguinte, o entrelaçamento de sua aprendizagem.

Sobre o conceito de portfólio, Frison e Veiga Simão (2011, p. 199), estudando as narrativas de formação inicial de professores, dilucidam este recurso como um instrumento metodológico aberto que agrega "ideias, conhecimentos, posturas e outras formas de se desenvolver o trabalho na escola, o que permitiu compreender, com mais clareza, a realidade escolar e o desenvolvimento das competências autoformativas".

Portanto, no contexto de formação, os portfólios são considerados instrumentos importantes, ao permitirem, no dizer de Veiga Simão e Flores (2006, p. 257), que os aprendizes "analisem, organizem e explicitem processos de aprendizagem de caráter diverso, desde conceitos científicos até conceitos mais pessoais de natureza autorreflexiva”. Esse fazer textual valoriza o que é experimentado provocando sua reflexão de forma a dimensionar o que ocorreu e tocou o sujeito da ação, em uma relação de diálogo consigo e com os outros. É um mecanismo autoformativo, visto ser o sujeito que seleciona, organiza, mobiliza e regula seus pensamentos que caracterizam as aprendizagens.

Nesse sentido, os portfólios de aprendizagem do estágio, utilizados na formação inicial de estudantes de Pedagogia, são instrumentos que evidenciam esses aspectos destacados e ajudam na compreensão dos processos autorregulatórios dos estudantes, e ainda, "a pertinência da visibilidade do entrelaçamento de experiências pessoais/profissionais com a autorregulação da aprendizagem, ou seja, o entendimento sobre o possível elo entre narrativas (auto)biográficas e aprendizagem autorregulada, no processo de formação de professores” (FRISON, VEIGA SIMÃO, 2011, p. 199).

\section{A importância da utilização das tecnologias nos contextos formativos}

As tecnologias atuais modificaram os sujeitos social e cognitivamente, requerendo comportamentos que atendam a dinamicidade do presente. Diferente talvez das implicações que tecnologias anteriores provocaram, a perspectiva mais marcante que as TIC formataram para a educação, a partir do fluxo contínuo de informação e das 
novidades tecnológicas constantes, foi a necessidade de desenvolvimento da competência do aprender a aprender, aprender ao longo da vida, que configura a capacidade de gerir o próprio conhecimento, bem como adaptar-se a novos contextos que surjam e solicitem outras habilidades (COUTINHO, LISBOA, 2011; KENSKI, 2012).

O aprender nesse novo paradigma necessita ser retroalimentado. É outra percepção do aprender, em que as relações que o sujeito estabelece com o meio (recurso) são mais complexas por envolver interações, escolhas e participação ativa, muito mais capazes de desenvolver e ampliar os sentidos, a imaginação, os valores e a constituição de si, de sua aprendizagem e da sociedade da qual faz parte. Por isso,

\begin{abstract}
Ensinar com e através das tecnologias é um binômio imprescindível à educação escolar. Não se trata de apenas incorporar o conhecimento das modernas tecnologias e suas linguagens. É preciso avançar. É preciso ultrapassar as relações com os suportes tecnológicos, possibilitando comunicações entre os sujeitos, e destes com os suportes tradicionalmente aceitos pela escola (livros, periódicos), até os mais atuais e muitas vezes não explorados no âmbito escolar (vídeos, games, televisão, Internet...). (PORTO, 2006, p. 49)
\end{abstract}

Educar frente a essas novas proposições e circunstâncias passa necessariamente por reposicionamentos das instituições educativas quanto ao cumprimento de seu papel, com a qualidade desejada. Nesses pressupostos, preconiza-se que as instituições educativas, os professores, os alunos e as formas de ensinar e aprender já não são mais as mesmas. Sendo outras, requerem novas intencionalidades educativas que atendam às necessidades cognitivas estimuladas pelas inovações tecnológicas (HARGREAVES, 2004). Assim, os profissionais da educação precisariam desenvolver outras competências que deem conta dessas novas demandas sociais (KENSKI, 2012).

A inserção das TIC nas práticas docentes passa antes pelo conhecer, apropriar e avaliar, de forma que as utilizações tenham intencionalidades pedagógicas. Consideramos essas premissas e reconhecemos a urgência e importância de usos eficientes das TIC na formação de professores, no sentido de fomentar reverberações nas práticas docentes nas escolas de educação básica. Para tanto é preciso promover alterações na formação de professores.

Sabemos que a qualidade das instituições educativas passa pelas práticas e formação dos professores, sendo importante favorecer apropriações de futuros docentes frente as TIC. Pensar as TIC no contexto da formação de professores é extrapolar sua 
simples presença e avançar nos sentidos e implicações de suas apropriações. Por isso são legítimos mecanismos que favoreçam as apropriações dos docentes. Para Ponte (2000, p. 76), o professor deve ter,

não só de aprender a usar constantemente novos equipamentos e programas,
mas também de estar a par das «novidades». No entanto, mais complicado do
que aprender a usar este ou aquele programa, é encontrar formas produtivas e
viáveis de integrar as TIC no processo de ensino-aprendizagem, no quadro dos
currículos actuais e dentro dos condicionalismos existentes em cada escola. O
professor, em suma, tem de ser um explorador capaz de perceber o que lhe
pode interessar, e de aprender, por si só ou em conjunto com os colegas mais
próximos, a tirar partido das respectivas potencialidades. Tal como o aluno, o
professor acaba por ter de estar sempre a aprender.

Quanto mais usos fazemos desses novos aparatos tecnológicos, mais apropriações que acarretem o desenvolvimento de um novo ethos docente efetivamos (BUZATO, 2009). Isso significa ocorrência ou potencialidade de transformação social, ancorada em participação, distribuição, experimentação, colaboração e hibridismo, que marcam as práticas de letramentos digitais dos sujeitos, sendo estes produtores e resultado das apropriações da cultura digital em que estão inseridos (LANKSHEAR, KNOBEL, 2005).

Sobre a apropriação, Buzato (2009) nos adverte que ela pode apresentar sentidos distintos quando posta em processo. Um deles diz respeito à apropriação como internalização da tecnologia, que, sendo objeto exterior ao sujeito, possui habilidades próprias que podem ser transmitidas a este. Por outro lado, também como objeto exterior, pode ser vista como um meio que está a serviço do sujeito, o qual a importa e a transforma de acordo com as suas necessidades. Por último, a apropriação da tecnologia é participativa, na ocasião em que "as pessoas adaptam e modificam o seu significado por meio da interação social (negociação de sentidos) em torno dos usos da tecnologia. Apropriação, portanto, passa de uma recondição a um sinônimo de transformação. Apropriar-se é igual a tornar-se (becoming)" (BUZATO, 2009, p. 4-5).

Dito isto, mesmo tendo como foco neste texto apresentar as reflexividades dos alunos de Pedagogia quanto aos usos das tecnologias nas escolas de educação básica, consideramos importante descrever os momentos trabalhados na disciplina, até a culminância da escrita que refletem as aprendizagens, que trazemos agora. 


\section{Atividades desenvolvidas no âmbito da disciplina e o cenário encontrado}

A dinâmica proposta na disciplina Informática Aplicada à Educação visou articular momentos formativos na universidade e nas escolas de educação básica. Foi efetivada durante o segundo semestre de 2017, com 36 alunos matriculados na disciplina, tendo como propósito problematizar os usos das Tecnologias em escolas da rede pública de ensino de Imperatriz -MA.

Primeiramente trouxemos à discussão a importância das tecnologias na educação de hoje. Subsidiados por textos de autores que se aproximam da questão, a exemplo de Lévy (2009), Castells (2006), Moran (2004) e Kenski (2012) dentre outros. Os alunos puderam articular alguns argumentos e estabelecer paralelos com o que vivenciavam na realidade das escolas do município, visto que alguns desses alunos já atuavam como docentes em escolas da rede pública ou privada de ensino. Vale destacar que a experiência desses alunos enriquecia nosso debate, visto trazerem dados empíricos durante nossas aulas.

Toda a discussão teórica serviu para compreendermos o panorama que as tecnologias trouxeram para a educação e levantar preocupações e perspectivas de inserção delas nas escolas, considerando as circunstâncias estruturais que encontrávamos na rede de ensino. Durante todas as discussões os alunos reconheciam a pertinência de trabalhar com as TIC nas escolas; que a secretaria de educação precisa disponibilizar recursos tecnológicos para as escolas; que os professores precisam utilizar computadores com internet e outros recursos de ponta; e também precisam se apropriar e se capacitar para usos educativos das tecnologias.

Posteriormente a essas problematizações pedimos que os alunos realizassem um levantamento de dados de cunho descritivo, de maneira que verificassem nas escolas algumas das questões postas. Elaboramos juntamente com eles um roteiro de perguntas a serem feitas aos professores regentes e um aluno por turma. As perguntas buscavam identificar se possuíam sala de informática e internet; verificar que outros recursos tecnológicos as escolas dispunham; se eram utilizadas pelos professores e com que frequência; e ainda quais tecnologias os alunos queriam que os professores utilizassem. No total pudemos visitar vinte e cinco escolas, que equivale a $17 \%$ da rede municipal e 1 
da rede federal. Todas localizadas na zona urbana, sendo a maioria localizada nas periferias da cidade.

Na questão existência ou não de salas de informática, os dados revelam que todas as 25 escolas possuíam um espaço reservado para os computadores fornecidos pelo governo federal, embora em oito delas os computadores já não estavam funcionando, além da falta de internet; em cinco delas os computadores funcionavam, mas não dispunham de internet; e somente 12 delas possuíam computadores e internet.

Com relação a existência de outros recursos nas escolas os dados revelam que estavam equipadas com as tecnologias mais convencionais, exceto a lousa interativa que pertencia à Escola Federal. Vejamos na figura 1.

Figura 1 - Recursos disponíveis nas escolas

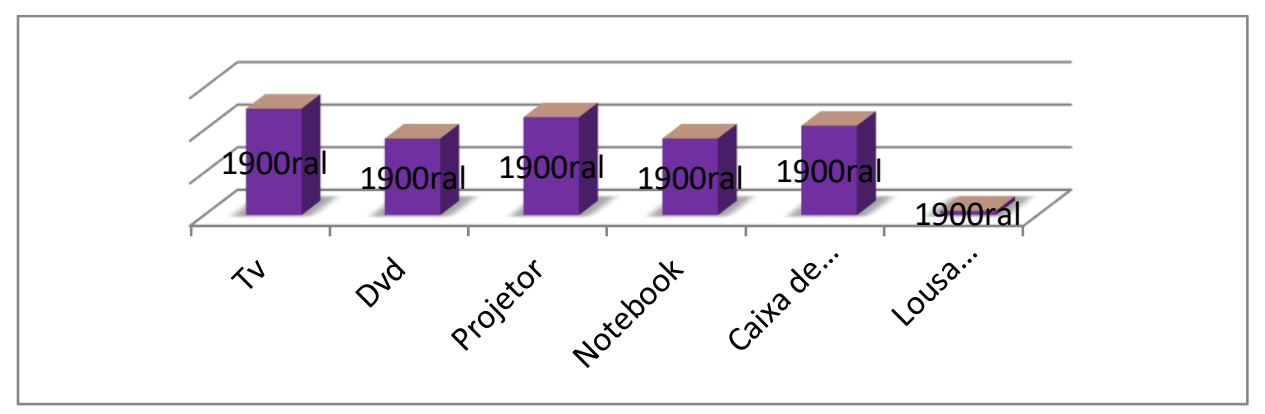

Fonte: Elaboração própria.

Ao que parece, essa é a realidade do município, que reflete a falta de expansão das políticas públicas educacionais, que deveriam fornecer equipamentos para as escolas, de forma que ampliassem as possibilidades de uso dos professores e alunos.

Com relação a utilização e a frequência desses recursos, treze professores afirmaram que utilizam os projetores numa frequência de uma a duas vezes por semana, para atividades elementares como exibição de vídeos nas aulas, que tivessem relação com o conteúdo que estava sendo trabalhado através do livro didático; 12 professores não faziam uso nenhum. A sala de informática era utilizada por três professores para pesquisas ou jogos uma vez por semana.

As respostas dos alunos ratificaram o que fora dito pelos professores quanto ao recurso que era utilizado, e revelaram também que gostariam que computadores com internet fossem utilizados nas aulas, destacando como justificativa de uso as pesquisas que poderiam realizar. Vale destacar que os alunos estão sinalizando para os professores 
e para escola a necessidade da inserção de outras tecnologias na dinâmica de aulas, e que parecem ter certa compreensão, indicar ou definir usos pedagógicos para tais.

No cenário nacional temos um crescimento quanto aos usos e incorporações de computadores e internet pelos professores nas escolas da educação básica no Brasil. Conforme pesquisa realizada pelo Centro Regional de Estudos para o desenvolvimento da Sociedade da Informação, dos 1810 pesquisados, 73\% utilizam em, ao menos, uma atividade semanal, e dentre as atividades mais destacadas estão as pesquisas sobre temas específicos, trabalhos em grupo, aulas expositivas e exercícios (CETIC.BR, 2017).

Esses dados têm seu aspecto positivo, porém também nos faz sugerir que esses usos ainda são elementares e seguem uma tendência mais operacional, aquém de suas potencialidades e distante da necessidade de incorporação eficiente e crítica em sala de aula. Talvez, considerando esses dados, estejamos mais próximos da situação escolar em que muda-se o recurso em sala de aula, mas os objetivos e a dinâmica de aula mantêm-se inalterados, o que indica que não é o uso que vai traduzir e garantir um projeto educativo inovador.

Avanços nas incorporações precisam ser feitos, eram as conclusões dos alunos. Isso os instigava, apesar do contexto problemático de recursos com que nos deparamos, a um maior empenho nos momentos formativos que se seguiam na disciplina, que se concentraram em planejar e desenvolver atividades que incluíssem um recurso tecnológico nessas turmas onde a coleta de dados se realizou.

As ações desenvolvidas nas escolas começaram a ganhar corpo nas práticas dos alunos entre os meses de agosto e setembro de 2017. Os temas trabalhados por eles nas turmas foram bastante variados: meio ambiente, numerais, cores, leitura de imagem, produção textual, dia dos pais, sustentabilidade, ECA. Quanto aos recursos, podemos destacar o uso de projetor, televisão, notebook e o celular como os que subsidiaram as propostas.

Por último, na tentativa de um exercício de reflexividade junto aos alunos, propusemos a escrita do que esse momento prático nas escolas com a utilização de tecnologias representou para eles. Essa questão foi lançada já no momento de planejamento das atividades, de maneira que pudesse ser refletida e respondida ao longo das atividades desenvolvidas nas escolas. Acreditamos que eles (os escritos) são importantes mecanismos de acesso às reflexões e apropriações promovidas pelos próprios 
sujeitos em seu processo (auto)formativo. Nesse contexto, trazemos, agora, escritos dos sujeitos em seus processos formativos como recursos que conduzem a (auto)formação docente.

\section{Usos e significados da tecnologia na prática dos aprendentes da docência}

No campo da formação de professores, os portfólios de aprendizagens podem ser vislumbrados na perspectiva dessa autorregulação, ao estimular as subjetivações dos discursos, controle e consciência dos processos próprios, pois é na escrita das experiências que a produção de sentidos em relação ao que foi vivido é construído e exposto. O exercício de escrita compreende o desenvolvimento de um novo processo que abrange a reformulação da experiência narrada.

A reflexividade da docência, quando percebida por tessituras escritas, ao mesmo tempo em que revela a dinamicidade da constituição dos processos formativos como um todo, possibilita também a captura de recortes propositivos específicos, que retratam as incorporações do sujeito em formação na constituição de uma identidade profissional. A escrita, nesse sentido, estabelece, segundo Blanchot (2010, p. 113), "o movimento da alternativa", de aproximações e afastamentos de nossas ações, reflexões e investigações.

Na captação da reflexividade, também aprendizagens construídas, selecionamos excertos de quatro alunos que cursaram a disciplina. O critério de escolha dos escritos se deu por trazerem mais claramente as suas percepções, aprendizagens e os esforços conjugados durante a imersão nas escolas. Com o intuito de preservar a identidade dos alunos, identificamos com a numeração de 1 a 4 .

\footnotetext{
A forma interativa como a temática foi abordada, com envolvimento dos alunos e com a valorização de suas vivências através das tecnologias, visa atender as exigências do que se espera da escola, das aulas e das formas de ensinar e aprender na sociedade atual. À medida que reconhece a importância da aprendizagem constante, permite que os alunos desenvolvam capacidades de gerir os conhecimentos e outras competências inerentes ao processo de aprender a aprender e, relacionar os conhecimentos e se relacionar com os mesmos. Em suma, concluímos que, com o uso das tecnologias, os alunos obtiveram uma aprendizagem significativa e puderam construir seus conhecimentos a partir dos conhecimentos prévios e das novas informações. Foi possível perceberem que são capazes de mudar sua realidade e ainda que a escola seja um lugar de construção de conhecimentos significativos, ou seja, necessários para a vivência das pessoas em sociedade, e que cada pessoa é responsável por suas ações e que mesmo agindo individualmente é capaz de atingir a coletividade (Sujeito 1, 2017).
} 
Percebemos que os recursos tecnológicos utilizados fizeram diferença na abordagem da temática, pois não apenas receberam informações, mas construíram conhecimentos sobre o assunto, resultando no documentário que fizemos. Sob essa temática, o trabalho pedagógico tornou-se mais envolvente e convidativo quando utilizamos meios e instrumentos que foram mais atrativos para os alunos. Assim a tecnologia favoreceu a propagação de conhecimento, incentivou a participação dos alunos, com a figura do professor como mediador, e possibilitou a comunicação e a troca de conhecimento entre sujeitos (Sujeito 2, 2017).

Considerando todas as dificuldades encontradas, inclusive a de estrutura da escola, já que as paredes de divisória das salas não são completas e daí há muito barulho que vem das salas de aula próximas, os resultados do trabalho foram melhores que o esperado. Foi importante para professora que viu uma das utilizações do celular em tempo real dentro da sala de aula. As crianças sentiram-se parte do processo construtor do conhecimento e durante as aulas todas queriam participar e ter a sua fala registrada e ouvida pelos colegas. A sala de aula é mais do que paredes que ensinam o currículo de alfabetização letrada e numérica. É preciso pensar na possibilidade de contribuir para a formação de cidadãos críticos e ativos na sociedade, preparados para o futuro. Utilizar de temas cotidianos e linguagem tecnológica é um dos passos que nos leva mais próximo a esta meta (Sujeito 3, 2017).

O desenvolvimento de sequência didática envolvendo o uso das TIC foi de fundamental aproveitamento por proporcionar, em situações reais de aprendizagem, a oportunidade de envolvimento dos alunos a partir de uma proposta inovadora que fugia da rotina diária dos mesmos, fato este que resultou em sua participação ativa (Sujeito 4, 2017).

Dada a complexidade que envolve as potencialidades, apropriação e uso competente, entendemos que a formação deve superar a perspectiva de domínio puramente técnico das tecnologias, sobretudo, deve enveredar-se por caminhos que favoreçam a construção de novas práticas educativas, pois o que está em questão na formação de professores não é a técnica instrumental, mas sim, para além dessa capacidade, perspectivar reflexões no contexto digital, ou ainda mais importante, uma mudança na concepção de aprendizagem do professor e formulação de outras trajetórias formativas (BARRETO, 2016).

Nessas falas, categorias como atividades significativas para a aprendizagem, inovação, desafios e possibilidades para o professor, compõem algumas nuances do que se desenhou nas práticas, que está em consonância com o que Kenski (2012, p. 67) já pontuava sobre as potencialidades da utilização de tecnologias na escola, ao afirmar que “educar para a inovação e a mudança significa planejar e implantar propostas dinâmicas de aprendizagem em que se possa exercer e desenvolver concepções sócio-históricas da educação, nos aspectos cognitivo, ético, político, cientifico, cultural, lúdico e estético." 
A competência digital coloca o professor diante de um novo paradigma, exigindo para além do domínio do conhecimento, a gestão e produção colaborativa deste, ou seja, o saber deixou de ser um ponto de chegada e passou a ser um ponto de partida para avançar no processo de construção do conhecimento e desenvolvimento de outras e novas habilidades, (UNESCO, 2009).

Não é possível mais conceber os alunos como receptores. Educar e aprender, na concepção desses grupos que aplicaram as atividades, pareceu-nos superar a visão de uma instrumentação técnica que as tecnologias preliminarmente sugerem, avançando muito mais no favorecer o desenvolvimento de dimensões e multifacetas que constituem os sujeitos na escola, que querem experimentar, explorar, interagir e ampliar suas capacidades.

Embora situadas no contexto específico da formação, essas questões dispostas condizem com as profundas mudanças e necessidades que a era digital trouxe para nosso cotidiano, não somente pelos novos recursos tecnológicos, mas também na configuração das relações sociais e formas de construir conhecimento (LEVY, 2009). Podemos dizer que as TIC ocupam hoje um largo e decisivo espaço na sociedade, formulando novos processos culturais que representam o balizamento de outras práticas sociais (SOARES, 2002), (BUZATO, 2009).

\section{Considerações Finais}

Compreendemos que os recursos tecnológicos oferecem inúmeras possibilidades de utilização. Nessa justaposição, dependendo da situação, concepção e uso, as consequências podem ser boas ou ruins, nunca neutras. Dito de outra maneira, as possibilidades dependem das aberturas ou restrições que os sujeitos impõem aos usos, representações e incorporações. Daí a necessidade de partir dos usos, para compreendermos as dinâmicas que conjugam as mudanças nos comportamentos dos sujeitos.

A sistemática adotada na disciplina, conforme descrito acima, traz algumas implicações para a formação dos alunos. O reconhecimento da emergência das TIC, a partir da fundamentação e da realidade posta na rede de ensino pública de Imperatriz MA, favorece reflexões sobre a complexificação dos processos de aprender e a 
necessidade de inovações no ensinar. Os alunos compreenderam que o novo paradigma despertado pelas TIC requer professores atualizados e em constante formação.

A inserção dos recursos tecnológicos ajudou a dinamizar as atividades que foram propostas nas escolas, que por sua vez favoreceu o desenvolvimento de outras competências, ou seja, a visão de que a atividade docente se baseia na transmissão de conteúdos pode ter sido alterada, visto que os nossos alunos vivenciaram e mobilizaram saberes e recursos para trabalharem de forma diferente.

Apesar do tempo que tivemos para desenvolver as atividades e as circunstâncias que o contexto apresentava, essa experiência pôde aproximar os alunos do seu campo profissional, que de forma crítica e criativa, fugiram do trivial e buscaram efetivar práticas que demonstrassem um maior potencial para a construção de sua identidade profissional em formação.

Obviamente, nossa pretensão ao sugerir essa vivência era mais no campo da singularidade, no sentido de levantar reflexões no uso dos recursos - mesmo os mais convencionais - pensando ser isso imprescindível aos docentes em formação, pois conduziria para outras possibilidades e outras formas de enxergar o processo educativo e a formação em questão.

A construção desses portfólios como instrumento de aprendizagem conduziu os aprendentes da docência a reflexões sobre as práticas e construção de saberes singulares, mas que podem formatar um movimento de identidade profissional. Pensamos que somente esse exercício de escrever e refletir sobre o vivido, o que fora desenvolvido terá implicações nas aprendizagens da docência.

É preciso avançar nas incorporações, e que estas, em contextos de formação, favoreçam o desenvolvimento em primeiro plano do profissional docente em sua completude, trazendo subsídios inclusive à ampliação da formação cultural dos professores, como se referem as diretrizes destacadas acima. Para tanto, não basta dizer em que o professor deve ancorar sua prática. Ele não é instrumento, é sujeito, como tal construtor ativo de seus processos. 


\section{Referências}

BARRETO, Marcelo Vatam. The e-book is on the tablet: novas mídias, velhas práticas no ensino de inglês? 2016. 270f. Dissertação (Mestrado em Educação) - Universidade Federal de Santa Catarina, 2016.

BLANCHOT, Maurice. A conversa infinita: a palavra plural. São Paulo: Escuta, 2001.

BUZATO, M. E. K. Letramentos digitais, apropriação tecnológica e inovação. In: III Encontro Nacional sobre Hipertexto, 2009, Belo Horizonte. Belo Horizonte: CEFETMG, 2009, 12p. Disponível em: http://nehte.com.br/hipertexto2009/anais/g1/letramentos-digitais-apropriacao-tecnologica.pdf. Acesso em: 27 nov. 2018.

CASTELLS, Manuel. A sociedade em rede. São Paulo: Paz e terra, 2006.

CETIC.BR. Pesquisa sobre o uso das tecnologias da informação e da comunicação nas escolas brasileiras 2017. Disponível em: https://cetic.br/publicacao/pesquisa-sobre-ouso-das-tecnologias-de-informacao-e-comunicacao-nas-escolas-brasileiras-ticeducacao-2017/. Acesso em: 20 dez. 2018.

COUTINHO, C; LISBOA, E. Sociedade da informação, do conhecimento e da aprendizagem: desafios para educação no século XXI. Disponível em: https://repositorium.sdum.uminho.pt/bitstream/1822/14854/1/Revista_Educa\%C3\%A7 \%C3\%A3o,VolXVIII,n\%C2\%BA1_5-22.pdf. Acesso em: 10 dez. 2018.

FRISON, L. M. B.; VEIGA SIMÃO, A. M. Abordagem (auto)biográfica - narrativas de formação e de autorregulação da aprendizagem reveladas em portfólios reflexivos. Educação, Porto Alegre, v. 34, n. 2, p. 198-206, maio/ago. 2011. Disponível em: http://revistaseletronicas.pucrs.br/ojs/index.php/faced/article/viewFile/8705/6357.

Acesso em: 12 nov. 2018.

HARGREAVES, A. O Ensino na sociedade do conhecimento: a educação na era da insegurança. Porto Alegre: Artmed, 2004.

JOSSO, Marie-Cristine. Experiências de vida e formação. 2. ed. Natal, RN: EDUFRN; São Paulo: Paulus, 2010.

KENSKI, V. M. Educação e tecnologias: o novo ritmo da informação. Campinas, SP: Papirus, 2012.

LANKSHEAR, C; KNOBEL, M. Digital Literacies: policy, pedagogy and research considerations for education. 2005. Disponível em: https://www.idunn.no/dk/2006/01/digital_literacy_and_digital_literacies__policy_pedagogy_and_research_cons. Acesso em: $10 \mathrm{dez} .2018$.

LÉVY, Pierre. Cibercultura. (Trad. Carlos Irineu da Costa). São Paulo: Editora 34, 2009. 
MORAN, J. M. Os novos espaços de atuação do professor com as tecnologias. Revista Diálogo Educacional, Curitiba, v. 4, n. 12, p. 13-21, Mai/Ago 2004. Quadrimestral.

PONTE, J. P. Tecnologia de informação e comunicação na formação de professores: que desafios? Revista Iberoamericana de Educación. n. 24 (2000), p. 63-90. Disponível em: http://repositorio.ul.pt/bitstream/10451/3993/1/00-Ponte\%28TIC-rie24a03\%29.PDF. Acesso em: 20 nov. 2018.

PORTO, T. M. E. As tecnologias de comunicação e informação na escola, relações possíveis, relações construídas. Revista Brasileira de Educação. v. 11, n. 31. jan./abr. 2006. Disponível em: http://www.scielo.br/pdf/rbedu/v11n31/a05v11n31.pdf. Acesso em: 15 jun. 2018.

POSTMANN, N. Tecnopolio. São Paulo: Nobel, 1994.

SILVA, Ivanda Maria Martins. Tecnologia e letramento digital: navegando rumo aos desafios. ETD - Educ. Tem. Dig. Campinas, v. 13, n. 1, p. 27-43, jul./dez. 2011. Disponível em: https://periodicos.sbu.unicamp.br/ojs/index.php/etd/article/view/1164. Acesso em: 20 nov. 2017.

SOARES, Magda. Novas práticas de leitura e escrita: letramento na cibercultura. Educação e Sociedade. Campinas, v. 23, n. 81, p. 143- 160, dez. 2002. Disponível em: http://www.cedes.unicamp.br. Acesso em: 17 ago. 2019.

UNESCO. Padrões de Competência em TIC para Professores. Tradução Cláudia Bentes David. Versão 1.0. Paris: UNESCO, 2009. Disponível em: http://unesdoc.unesco.org/images/0015/001562/156209por.pdf. Acesso em: 10 nov. 2018.

VEIGA SIMÃO, A. M; FLORES, A. O aluno universitário: aprender a auto-regular aprendizagem sustentada por dispositivos participativos. Revista Ciências e Letras, Faculdade Porto-Alegrense, Porto Alegre, n. 40, p. 216-29, jul./ dez. 2006. 